
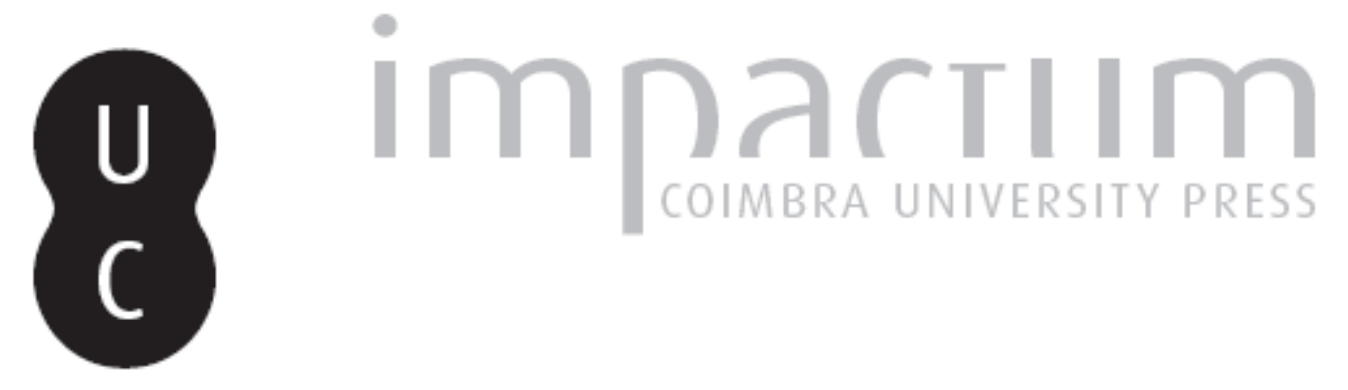

\title{
[Recensão a] José Manuel Garcia, Epigrafia Lusitano-Romana do Museu Tavares Procnça Júnior
}
Autor(es):
Mantas, Vasco Gil

Publicado por: Imprensa da Universidade de Coimbra

URL persistente:

URI:http://hdl.handle.net/10316.2/45663

DOI:

DOI:https://dx.doi.org/10.14195/1647-8657_24_11

Accessed : $\quad$ 26-Apr-2023 13:22:10

A navegação consulta e descarregamento dos títulos inseridos nas Bibliotecas Digitais UC Digitalis, UC Pombalina e UC Impactum, pressupõem a aceitação plena e sem reservas dos Termos e Condições de Uso destas Bibliotecas Digitais, disponíveis em https://digitalis.uc.pt/pt-pt/termos.

Conforme exposto nos referidos Termos e Condições de Uso, o descarregamento de títulos de acesso restrito requer uma licença válida de autorização devendo o utilizador aceder ao(s) documento(s) a partir de um endereço de IP da instituição detentora da supramencionada licença.

Ao utilizador é apenas permitido o descarregamento para uso pessoal, pelo que o emprego do(s) título(s) descarregado(s) para outro fim, designadamente comercial, carece de autorização do respetivo autor ou editor da obra.

Na medida em que todas as obras da UC Digitalis se encontram protegidas pelo Código do Direito de Autor e Direitos Conexos e demais legislação aplicável, toda a cópia, parcial ou total, deste documento, nos casos em que é legalmente admitida, deverá conter ou fazer-se acompanhar por este aviso.

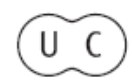


FACULDADE DE LETRAS

INSTITUTO DE ARQUEOLOGIA

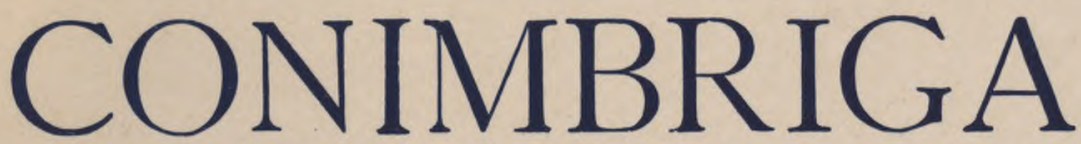

VOLUMEXXIV

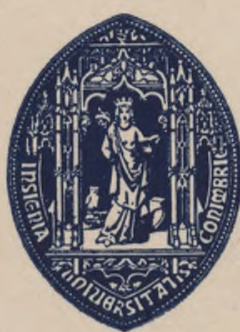

UNIVERSIDADE DE COIMBRA

1985 
siadamente simplificado, reflectindo quer as opções do autor, quer os condicionalismos, de uma investigação apenas iniciada, como tão evidentemente demonstra o quadro incluído na página 148: em 93 villae, ou estabelecimentos assim classificados, 44 foram referenciados por dados epigráficos, enquanto que a prospecção permitiu identificar 31 sítios; as sondagens e escavações verificaram-se apenas em 7 estações. Tais limitações, perfeitamente admissíveis, de maneira nenhuma desvalorizam a obra de Baumann, que, a par de outros trabalhos já publicados sobre a mesma região (A. Aricescu, Armata in Dobrogea romanã, Bucareste, 1977; A. Suceveanu, Viata economicâ in Dobrogea romanã, Bucareste, 1977), fica a constituir um elemento de consulta obrigatória. Apenas lamentamos que a qualidade das cartas dificulte por vezes a compreensão do texto e que a ausência de indices torne difícil a utilização da obra. Sem pretender ser uma síntese, mas sim um ponto de partida (p. 9), este trabalho, patrocinado pelo Museu do Delta do Danúbio, permite um melhor conhecimento da implantação romana na região, não escondendo os numerosos problemas próprios de uma investigação quase pioneira e de uma assunto tão atraente como complexo: o das estruturas rurais. Baumann afirma-se como um arqueólogo completo, capaz de unificar num estudo coerente as informações obtidas em fontes de tipo muito diverso, oferecendo aos investigadores uma obra muito feliz, em tudo digna do notável esforço da arqueologia romena para recuperar e dar a conhecer uma história que, por ser real, é ainda mais admirável do que a da crónica de Cantemir, enriquecendo, simultaneamente, os laços de união entre os povos latinos.

VASCo Gil Mantas

José Manuel Garcia, Epigrafia Lusitano-Romana do Museu Tavares Procnça Júnior, Museu de Tavares Proença Júnior, Castelo Branco, 1984, 187 p., 27 est., 1 mapa desdobrável.

Uma das áreas de maior interesse para o estudo da epigrafia luso- romana é, pela abundância e características dos monumentos regionais, a que corresponde modernamente ao Distrito de Castelo Branco. Basta recordar a impressionante colecção de inscrições conservada em Idanha-a-Velha, a qual, tendo em conta a sua origem, se pode considerar, com as suas quase 200 epígrafes, como a mais importante do País. Não é de estranhar, portanto, que os epigrafistas se tenham ocupado com frequência do estudo de material tão propicio, nem sempre, infelizmente, da forma mais conveniente. Como reflexo desse interesse surgiu últimamente, publicado pelo Museu de Tavares Proença Júnior, o catálogo da colecção de epigrafia luso-romana desta instituição cultural da capital da Beira-Baixa, da autoria de José Manuel Garcia. O referido trabalho pretende colmatar uma lacuna importante, reunindo num volume de agradável 
aspecto gráfico informação relevante sobre as inscrições existentes no Museu, com particular destaque para os monumentos encontrados na região, 10 dos quais se encontravam inéditos.

A organização do volume é um pouco complicada, não tendo resultado por completo o intento, enunciado pelo autor, de conciliar no texto do catálogo o geral e o particular (p. 9). Não julgamos fácil a solução do problema mas pensamos que um catálogo se deve concentrar no que é verdadeiramente essencial e recordamos que, á data da redacção inicial do trabalho, J. M. Garda dispunha de um óptimo modelo no catálogo epigráfico da Sociedade Martins Sarmento (Mário Gardozo, Catálogo do Museu de Martins Sarmento. Secção de Epigrafia Latina e de Escultura Antiga, Guimarães, 1972²). Na primeira parte (p. 12-32), o autor começa por referir brevemente a figura do patrono do Museu e as vicissitudes históricas da instituição, passando em seguida a tecer algumas considerações sobre a ciência epigráfica e sobre a romanização. Ainda na mesma divisão inclui observações acerca da tipología e proveniência das peças e indica a metodologia que utilizou na publicação das mesmas, terminando com a lista da bibliografia e das abreviaturas. $\mathrm{Na}$ segunda parte, Garcia apresenta as inscrições votivas (p. 35-85), as inscrições funerárias (p. 87-132), as marcas e grafitos (p. 133-136), os fragmentos de aras anepígrafas (p. 137-139), as peças consideradas perdidas ou ausentes do Museu (p. 141-145) e uma breve conclusão (p. 147). O volume termina com as estampas (p. 149-175), vários índices (p. 177-182) e uma adenda (p. 183-185).

J. M. Garcia informa que a obra, apesar de concluída em Setembro de 1979, só em 1984 foi dada à estampa, por dificuldades várias, tendo sofrido apenas ligeiros retoques (p. 147). Por isso estranhamos que a adenda inclua a marca de um peso de tear recolhido no Museu em 1916 (p. 184), enquanto que na bibliografia se referem várias publicações posteriores a 1979 (p. 31). Teria sido preferível, pensamos, refundir o trabalho de forma a eliminar elementos menos precises, tanto mais que se trata de pequenas alterações. Antes de analisarmos mais detidamente algumas das inscrições publicadas por J. M. Garcia não podemos deixar de formular uma ou outra observação que nos parece mais pertinente quanto à organização e conteúdo deste catálogo. Em relação ao primeiro ponto gostaríamos de deparar, como já dissemos, com um texto desimpedido de passagens cuja inserção na economia geral da obra resulta por vezes discutível, senão inútil. Estão nesse caso, por exemplo, parte das páginas dedicadas à romanização (p. 17-21) e à problemática religiosa luso-romana (p. 43-44). Por outro lado, quer a análise da romanização, já citada, quer a caracterização da colecção epigráfica do Museu (p. 23-25), assumem um conteúdo conclusivo, contrariando uma metodologia rigorosa, dado que antecedem o estudo dos monumentos. Outro aspecto que nos parece também menos correcto é o de considerar no catálogo peças desaparecidas (p. 143-145), tanto mais que não houve unidade de critério: incluindo a inscrição de Caudicus e de Casina (p. 143), publicada depois de Tavares Proença por Fernando de Almeida (F. Almeida, Egitânia. História e Arqueologia, Lisboa, 1956, n. ${ }^{\circ}$ 56, p. 177, 452), o que c autor não 
refere, teria sido necessário transcrever todas as que do Museu foram transferidas para Idanha-a-Velha (p. 145), pois é na velha Egitânia que aquela, como estas, se encontram; assim fica resolvido o problema do paradeiro desta epígrafe, que tivemos oportunidade de estudar em 1982, durante os trabalhos de revisão do espólio epigráfico de Idanha-a-Velha. Quanto às estampas, de dimensões muito aceitáveis, é pena que a fraca qualidade de algumas não permita a leitura dos textos. J. M. Garcia elaborou vários índices dos quais os mais importantes são o teonímico (p. 177-178), o antroponímico (p. 178-179) e o geográfico (p. 181-182), alargando a capacidade de utilização da obra como instrumento de trabalho, tanto mais que indicou as leituras duvidosas ou menos seguras. Um índice de equivalências bibliográficas, não inserido, seria igualmente muito útil, permitindo uma maior segurança na identificação des textos.

Debrucemo-nos agora sobre algumas afirmações mais merecedoras de reparo. Por exemplo, não nos parece justa a opinião expressa pelo autor acerca da raridade dos catálogos epigráficos em Portugal (p. 9), dado que não corresponde à realidade (José d'Encarnação, Introdução ao Estudo da Epigrafia Latina, Coimbra, 1979, p. 38-40). J. M. Garcia escreve que as informações obtidas a partir de testemunhos epigráficos se conseguem «através da leitura e interpretação do que nesse material foi gravado para a posteridade» (p. 15). Não esqueçamos, todavia, qus não foi para nós que os antigos gravaram as suas inscrições, mas sim para a sua própria época e para a sociedade em que viviam. Sa assim não fosse seria fácil a interpretação dos textos epigráficos, operação que exige amplos conhecimentos históricos e culturais, que ultrapassam largamente a simples capacidade de ler e traduzir o Latim, já de si tão reduzida nos nossos dias. Mais adiante, ao tratar dos problemas da romanização da Beira Baixa, o autor considera o vicus como o aglomerado populacional predominante na zona durante a Época Imperial (p. 18-19), embora reconheça que a ausência de escavações obrigue a encarar tal opinião como uma hipótese, a qual, na nossa opinião, tem francas probabilidades de vir a ser comprovada, nomeadamente a partir de trabalhos sistemáticos em estações já identificadas, como por exemplo, a de S. Lourenço, perto de Monsanto, que julgamos corresponder a um vicus. Uma afirmação que se prende com os castros romanizados, formulada a propósito das modificações do habitat tradicional (p. 19), é bastante mais discutível, pois na realidade quase todos os castros conhecidos foram romanizados (C. A. Ferreira de Almeida, $O$ castrejo sob o domínio romano: a sua transformação, «Estudos de Cultura Castrexa e de História Antiga de Galicia», Santiago de Compostela, 1983, p. 187-198). Outra afirmação difícil de apoiar é a de que os magistri referidos numa célebre inscrição de Idanha-a-Velha (ILER 2082) representem potentados locais (p. 20), no sentido económico do termo, pois deles apenas conhecemos os nomes. Quando se verificam alterações tão importantes como as que caracterizaram a romanização, pode bem ter sucedido que uma parte das elites locais represente uma classe ascendente que tenha aproveitado o colaboracionismo para se afirmar social e economicamente. Também julgamos pouco fundamentada a opinião do autor acerca da causa 
que teria determinado o predomínio, na região da Beira Baixa, das inscrições votivas sobre as funerárias, resultante, segundo Garcia, de uma preferência pelas «novas formas de adoração dos deuses», enquanto que «a população rústica sentiria pouco a necessidade de se assinalar para a posteridade com epitáfios» (p. 24-25). Dado que parte importante das epígrafes se pode relacionar com santuários indígenas, como o que existiu em S. Martinho, nos arredores de Castelo Branco, não nos parece difícil compreender a diferença em questão, atribuindo-a sobretudo ao facto mencionado, à fortuna das descobertas arqueológicas e à falta de documentação. Que ideia poderíamos formular, por exemplo, da epigrafia do distrito de Évora se, para além das inscrições da capital alentejana e de algumas dispersas, conhecêssemos apenas as epígrafes votivas do santuário de S. Miguel da Mota?

Em relação às referências bibliográficas corrigimos duas indicações: Maria de Lourdes Albertos, Nuevos antropónimos hispánicos, «Emerita», XL, 1972, p. 1-29, 287-318; Justino Mendes de Almeida, Varia Epigraphica «Revista de Guimarães», LXXXV, 1975, p. 95-96.

Depois de sumariar em breves páginas o desenvolvimento dos trabalhos de síntese sobre divindades indígenas interessando ao território português específicas do mesmo, onde o CIL II é referido de forma algo confusa e sem alusão às adendas da Ephemeris Epigraphica (p. 39), J. M. Garcia tece algumas considerações, por vezes muito concretas, acerca do problema do sincretismo religioso luso-romano (p. 43-44), tema por demais bem conhecido do autor e ao qual tem dedicado notável esforço.

Passemos em seguida ao catálogo propriamente dito. As inscrições estão ordenadas por tipos, de forma pouco sistemática: textos votivos e textos funerários sucedem-se respectivamente por ordem alfabética dos teónimos e por ordem alfabética do local de achado, neste caso com excepção das inscrições de Collipo e de Conimbriga, que ocupam o final da enumeração. O esquema geral do estudo de cada peça compreende a indicação do n. ${ }^{\circ}$, idêntico ao da fotografia, texto em caracteres epigráficos — desnecessário-, local do achado e paradeiro, dimensões, texto desenvolvido, tradução, altura das letras, comentário sucinto e bibliografia. Sem pretendermos ser exaustivos e porque a qualidade das fotos dificulta a apreciação, faremos apenas algumas sugestões e comentários que consideramos mais oportunos:

- n. ${ }^{\circ}$ 1: pensamos que se trata de uma ara consagrada não a uma divindade indígena mas sim a Liber e Libera, teónimos que cremos preencherem as duas últimas linhas, precedidas pelo nome do doador. Liber e Libera são divindades tipicamente romanas cujo culto está atestado em vários locais da Lusitânia (Robert Étienne-Georges Fabre, Epigraphie et Sculpture, «Fouilles de Conimbriga», II, Paris, 1977, n. ${ }^{\circ}$ 13, p. 33-34; José d'Encarnação, Inscrições Romanas do Conventus Pacensis, Coimbra, 1984, n..$^{\circ}$ 567, p. 634), nomeadamente em Monsanto (F. Almeida, Egitânia, p. 378-379, fig. 188).

— n. ${ }^{\circ}$ 2: não compreendemos por que razão os nexos de TANGINI/ /GIAECO são indicados de duas formas, através de um traço hori- 
zontal e geminando as letras; verifica-se um lapso na translineação da mesma palavra.

- n. ${ }^{\circ}$ 3: o monumento poderá ter sido, como supõe o autor, consagrado a uma divindade do grupo Band, que pensamos ser a mesma da inscrição n. ${ }^{\circ} 18-$ Bañáis Vorteaeceus.

—n. ${ }^{\circ}$ 5: na 1.4 , o ponto sob o $\mathrm{S}$ não se justifica.

- n. ${ }^{\circ}$ 7: ao contrário do que J. M. Garcia considera, uma observação mais atenta da epígrafe permitirá acrescentar mais alguma coisa ao texto desta interessante ara consagrada a Júpiter Óptimo Máximo: na última linha, por exemplo, lê-se perfeitamente a palavra [LjIBENS.

- n. ${ }^{\circ}$ 9: a inscrição de Idanha-a-Velha merece algumas reservas (F. Almeida, Egitânia, n. ${ }^{\circ}$ 9, p. 148).

- n. ${ }^{\circ}$ 10: esta inscrição já esteve em ldanha-a-Velha (F. Almeida, Egitânia, n. ${ }^{\circ}$ XII, p. 268, fig. 175), daí o erro de localização em ILER 675; não cremos que o território de Cauria se estendesse até ao rio Aravil, mesmo que CAIRIESIBVS esteja por Cauriesibus.

- n. ${ }^{\circ} 1$ :este monumento, consagrado a Trebarona, suscita numerosos problemas de leitura, não nos satisfazendo por completo a lição do autor: na 1. 5, parece-nos possível interpretar como $\mathrm{D}(\mathrm{e}) \mathrm{S}(\mathrm{no})$ $\mathrm{P}$ (osuit) $\mathrm{MAG}$ (ister) ou $\mathrm{D}(\mathrm{e}) \mathrm{S}($ uo $) \mathrm{P}$ (er) $\mathrm{MAG}$ (istrum) $\backslash$ não vemos como relacionar PROTAE (?) com SACERDOS, que é efectivamente o que se lê na 1. 4 .

— n. ${ }^{\circ}$ 15: julgamos a leitura [ARjCONIS.F a mais aceitável.

- n. 16: parece-nos difícil que num monumento perfeitamente clássico, em que a antroponímia é clássica, as relações sociais de tipo romano e a divindade-Victoria — típica da ideologia imperial, se possa identificar um sincretismo com Trebaruna.

- n. ${ }^{\circ}$ 17: a ocorrência dos tria nomina indicados por siglas já se verificou nesta região em monumentos votivos (Fernando de Almeida, Aras inéditas, igeditanas, dedicadas a Marte, «Revista da Faculdade

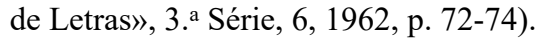

- n. ${ }^{\circ}$ 22: Fernando de Almeida desconhecia o paradeiro desta inscrição (Egitânia, n. ${ }^{\circ} 28$ p. 160); na 1. 6, ainda é visível o $\mathrm{F}$ da fórmula D.S.F.C.

- n. ${ }^{\circ}$ 23: é pouco viável a classificação do elemento decorativo que termina a inscrição como hedera.

- n. ${ }^{\circ}$ 24: atendendo à qualidade da fotografia limitaremos o nosso comentário ao problema da localização de Concordia, cidade que, segundo o autor, devia situar-se na área de Castelo Branco. $\mathrm{Na}$ realidade não encontramos nenhum elemento na argumentação apresentada que autorize tal localização, tanto mais que a referência à origem normalmente indica afastamento do local do achado (José d'Encarnação, Sociedade Romana e Epigrafia, Setúbal, 1979, p. 49-50); acrescentemos ainda que a tradução está incompleta e que a leitura Con[treb]iensi é igualmente possível. 
- n. ${ }^{\circ}$ 25: não compreendemos por que razão a origem indoeuropeia de Ammius e de Avitus deveria limitar a sua difusão na Europa Ocidental.

— n. ${ }^{\circ}$ 28: propomos a seguinte tradução: Aos deuses Manes. Título, filho de Rusticano, de setenta e cinco anos. A esposa, Galácia (?), colocou (este monumento).

- n. ${ }^{\circ}$ 29: Fernando de Almeida desconhecia o paradeiro deste monumento [Egitánia, n. ${ }^{\circ} 37$, p. 165-166); dado que o dedicante é filho de liberto é natural que não aluda ao pai.

- n. ${ }^{\circ}$ 30: Fernando de Almeida desconhecia o paradeiro desta inscrição [Egitánia, n. ${ }^{\circ}$ 42, p. 168); a indicação bibliográfica do autor está errada.

— n. ${ }^{\circ}$ 31: a lição de J. M. García prevalece sobre as anteriores.

— n. ${ }^{\circ}$ 32: Fernando de Almeida desconhecia o paradeiro desta epígrafe íEgitánia, n. ${ }^{\circ} 123$, p. 129); a leitura correcta é a do autor; nal. 1, a sigla $\mathrm{F}$ é visível.

— n. ${ }^{\circ}$ 37: na 1. 2, é possível 1er ... AVLIVS PATERNI F; julgamos mesmo que se pode tentar uma leitura mais completa.

— n. ${ }^{\circ}$ 38: o monumento, apesar de tudo, merece um esforço maior:

1. 5: MATER D S F C; o autor supõe que o cipo foi levado de Idanha-a-Velha em 1972, hipótese com que concordamos e que alargamos às inscrições n. ${ }^{\text {os }} 36$ e 37.

- I (adenda, p. 183-184): entendemos que a interpretação do texto não permite identificar Fadia como filha, pois que pode tratar-se da mãe do segundo C.Vibius; por outro lado, há um lapso no desenvolvimento da hipotética fórmula final, pois sendo dois os dedicantes, como pretende J. M. Garcia, deve ser F(aciendum) C(uraverunt).

Como actividade científica, a investigação epigráfica, renovada em Portugal desde há uma dezena de anos, exige grande rigor e disciplina, pelo que o presente catálogo deve merecer a atenção do seu autor no sentido de uma refundição, de forma a torná-lo num instrumento de trabalho ainda mais útil, eliminando passagens obscuras (p. 25, 37, 89, 119, 184), rectificando leituras, acertando referências. J. M. Garcia certamente estará á altura da tarefa, valorizando um trabalho cuja importância se afirmará com o tempo. 